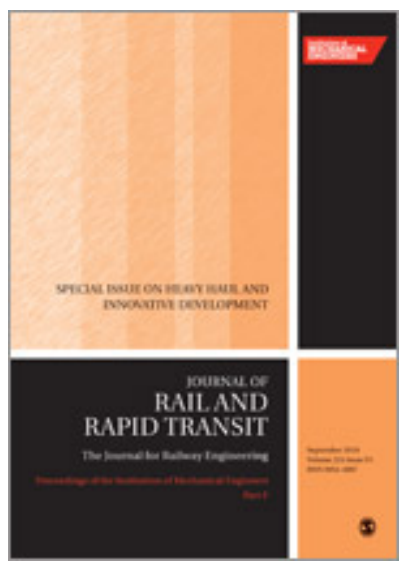

\title{
Novel technology concepts and architecture for on-board condition-based monitoring of railway running gear: the RUN2Rail vision
}

\begin{tabular}{|c|c|}
\hline Journal: & Part F: Journal of Rail and Rapid Transit \\
\hline Manuscript ID & JRRT-19-0264.R1 \\
\hline Manuscript Type: & Article \\
\hline $\begin{array}{l}\text { Date Submitted by the } \\
\text { Author: }\end{array}$ & 06-May-2020 \\
\hline Complete List of Authors: & $\begin{array}{l}\text { Martin Jarillo, Julian; Metro de Madrid, Engineering } \\
\text { Moreno Garcia-Loygorri, Juan; Universidad Politecnica de Madrid, } \\
\text { Ingenieria Audiovisual y Comunicaciones; Metro de Madrid, Engineering } \\
\text { Alfi, Stefano; Politecnico di Milano, Dipartimento di Meccanica } \\
\text { Barcet, Sylvain; Vibratec } \\
\text { Bouvet, Pascal; Vibratec } \\
\text { Bruni, Stefano; Politecnico di Milano, Dipartimento di Meccanica } \\
\text { Cervello, Steven; Lucchini } \\
\text { Costa, Bruno; - } \\
\text { Licciardello, Riccardo; SAPIENZA Universita' di Roma, DICEA Department } \\
\text { of Civil, Building and Environmental Engineering }\end{array}$ \\
\hline Keywords: & $\begin{array}{l}\text { condition-based maintenance, Rolling stock, rolling stock design, running } \\
\text { gear, railways, railway technology }\end{array}$ \\
\hline Abstract: & $\begin{array}{l}\text { Bogies are key subsystems for rolling stock safety and, therefore, } \\
\text { meaningful and objective data concerning their condition is of paramount } \\
\text { importance for railway operation. These subsystems experience severe } \\
\text { service conditions causing wear, damage and degradation of components } \\
\text { and affecting the vibrations to which the passengers are exposed. As } \\
\text { such, safe and reliable operation, together with a high level of comfort } \\
\text { for the passengers, can only be assured by an in-depth, data-based and } \\
\text { comprehensive maintenance of the bogie components. In this } \\
\text { perspective, advanced health monitoring of the running gear plays a } \\
\text { fundamental role as the enabler for condition-based maintenance } \\
\text { strategies. } \\
\text { This paper reports about work performed in the RUN2Rail project aimed } \\
\text { at formulating new concepts for the condition monitoring of the running }\end{array}$ \\
\hline
\end{tabular}


gear. Three case studies are addressed: wheelsets, powertrain and suspension components. For these cases, the suitable choice and location of sensors is investigated and innovative fault detection and fault classification methods are proposed and preliminarily validated by means of numerical experiments and laboratory tests. A concise outline of the impacts and benefits of each proposed condition monitoring application is also provided.

\section{SCHOLARONE ${ }^{\text {M }}$ Manuscripts}




\title{
Novel technology concepts and architecture for on-board condition-based monitoring of railway running gear: the RUN2Rail vision
}

\author{
Julián Martín Jarillo ${ }^{1}$, Juan Moreno ${ }^{1}$, Stefano Alfi ${ }^{2}$, Sylvain Barcet ${ }^{3}$, Pascal Bouvet ${ }^{3}$, \\ Stefano Bruni ${ }^{2}$, Steven Cervello ${ }^{4}$, Bruno Costa ${ }^{5}$, Riccardo Licciardello ${ }^{5}$ \\ ${ }^{1}$ Metro de Madrid ,S.A., Madrid, Spain \\ ${ }^{2}$ Politecnico di Milano, Milano, Italy \\ ${ }^{3}$ Vibratec, Lyon, France \\ ${ }^{4}$ Lucchini R.S. SpA, Lovere, Italy \\ ${ }^{5}$ Università degli Studi di Roma La Sapienza, Roma, Italy
}

\section{Abstract}

Bogies are key subsystems for rolling stock safety and, therefore, meaningful and objective data concerning their condition is of paramount importance for railway operation. These subsystems experience severe service conditions causing wear, damage and degradation of components and affecting the vibrations to which the passengers are exposed. As such, safe and reliable operation, together with a high level of comfort for the passengers, can only be assured by an in-depth, data-based and comprehensive maintenance of the bogie components. In this perspective, advanced health monitoring of the running gear plays a fundamental role as the enabler for condition-based maintenance strategies.

This paper reports about work performed in the RUN2Rail project aimed at formulating new concepts for the condition monitoring of the running gear. Three case studies are addressed: wheelsets, powertrain and suspension components. For these cases, the suitable choice and location of sensors is investigated and innovative fault detection and fault classification methods are proposed and preliminarily validated by means of numerical experiments and laboratory tests. A concise outline of the impacts and benefits of each proposed condition monitoring application is also provided.

\section{Introduction}

The development of a new generation of running gear in railway vehicles is desirable to reduce life-cycle costs (LCC) and improve reliability, to achieve a higher energy efficiency and to minimize noise emissions. These four objectives are the pivotal aspects of the RUN2Rail Project [1], which is ascribed under the Shift2Rail Program co-funded by the EU [2]. In particular, the medium-term aim is to develop a running gear technology demonstrator to help the design of future rolling stock. However, for the sake of efficiency, the idea is not to 'reinvent the wheel', furthermore relying when possible on COTS (Commercial-Off-The-Shelf) products and recycling as many results as possible from previous related projects. 
In this perspective, the continuous health monitoring of the running gear plays a fundamental role as it enables the move from the preventive maintenance strategies now in use towards condition-based maintenance [3]. The advantages offered by condition-based maintenance are in terms of cost savings, because maintenance is performed only when needed, but also in terms of reducing unexpected in-service failure of the running gear, eventually resulting in enhanced reliability and availability together with optimized life cycle costs [4].

In particular, the main objective of this paper is the formulation of technology concepts for condition monitoring systems (CMS) to be applied in the next generation of railway running gear. Therefore, we address three case studies, namely: wheelsets, bearings and gearboxes and, finally, suspensions. In all of them we identify solutions and components already available on the market (sensors, DSP, communications, etc.) taking into account potential synergies with the industrial and automotive sectors in order to formulate initial concepts for CMS, define a global system architecture for the on-board CMS and, finally, specify system requirements for the three case studies considered. Methods for fault detection and identification are also presented for the three case studies and their performances are assessed by means of numerical experiments and laboratory tests.

This paper is structured as follows: Section 2 reports the results of investigations performed by the RUN2Rail team in order to identify solutions already available, both as products available on the market in different sectors (including railways) and concepts that have been developed up to technology readiness levels (TRL [3]) 4-5. Section 3 describes the needs for condition monitoring $(\mathrm{CM})$ in the running gear of modern railway vehicles, mostly based on experience and return from operation at Metro de Madrid, the railway operator included in the RUN2Rail Consortium. Section 4 describes the concepts elaborated for the system architecture, with a TRL between 2 and 5. Section 5 provides an overview of the systems and operational requirements for the condition monitoring systems; and, finally, Section 6 presents some conclusions for the work.

\section{State-of-the-Art of running gear condition monitoring}

Due to safety-critical components involved in rolling stock, periodic maintenance operations and inspections are performed to guarantee their integrity and good level of performance. Maintenance actions are often based on a preventive scheme, i.e. the rolling stock is inspected, and components are replaced based on time intervals and/or on the mileage run. In recent years, however, more advanced condition-based maintenance strategies have been progressively applied for railway rolling stock [15]. In this latter case, inspection and replacement is performed based on the knowledge of the component's health state coming from a suitable condition monitoring system. The advantages of adopting a predictive condition-based maintenance scheme are the reduction of in-service failure, as components are replaced before reaching a critical health state and, at the same time, improvement of Life Cycle Costs (LCC). In fact, maintenance costs will be reduced since components can be operated until they approach the end of their useful life, whilst with preventive maintenance components are often replaced earlier, due to the lack of 
knowledge of the actual working conditions and hence the need to use conservative assumptions in the estimation of their service life.

Condition-based maintenance schemes require that advanced condition monitoring methods are available in order to diagnose efficiently the current health state of the components and to recognise signs of incipient failure from suitable measured signals and indicators. Examples of this approach have been proposed in the past, e.g. in [4], [5], [6].

Typical failure of critical components of running gear are listed in Table 1 along with current and innovative condition monitoring solutions.

Rolling surface defects, such as flats, rolling contact fatigue (RCF) defects on the wheel rolling surface and thermal cracks on disc brakes, can be inspected with different techniques:

Visual.

Wayside sensors are in some limited cases installed to monitor track vibration during vehicle pass by with the purpose of identifying defective wheelsets.

Continuous monitoring of on board vibration levels can detect rolling surface defects from a very initial stage since vibration levels rapidly rise. See [7] [8].

Degradation of the transversal profile of the wheel due to wear can be detected with different techniques:

Manually with specific gauges to evaluate some profile parameters or more in detail with manual laser optical equipment that provides the complete profile.

Wayside laser optical systems work automatically during the pass by of the vehicle at limited speed.

Based on the theory of wheelset dynamics, hunting instability is affected by the increasing wear of the wheels due to the changing of the equivalent conicity. Thus, continuous monitoring of periodic vibration levels in a well known range of frequency can predict wear of the wheels.

Axle surface defects, as potential crack precursors, can be inspected as follows:

Visual inspection of conting integrity and related indentations and local corrosion pit phenomena.

Wayside camera systems have been recently developed in order to altomatically record images of the vehicle passing by and recognizing some types of visible irregularity such as missing parts, paint detachments or corrosion in the bogie system. 
Axle crack inspection due mainly to fatigue or corrosion fatigue can be performed by:

Ultrasound techniques using portable systems that inspect hollow axles from the inside or solid axles from the head. These methods require the withdrawal of the vehicle from service and expert operators.

In order to optimize the periodicity of ultrasound based inspection through better knowledge of crack behaviour, the loads accumulated by the axle since it entered service may be measured by means of an autonomous strain-gauge based acquisition system installed on each axle.

Dimensional checks in order to keep under control relevant dimensions of the bogie system such as wheelset gauge, wheel diameter or brake pad thickness can be performed as follows:

Manual techniques, that involve stopping the vehicle with a consequent decrease in availability.

Wayside measurement with optical systems.

Gearbox failures including teeth and bearing defects that can be inspected by:

Visual inspection, that involves the disassembly of the component.

Oil analysis [9] [10], which can be performed automatically using e.g. a monitoring system like the one shown in Figure 1, consisting of two electrodes (mounted on a plug): one of them magnetized to attract ferromagnetic particles contained in the oil. When there are enough particles attracted by the magnet, the two electrodes become electrically connected and an alarm is triggered. This alarm is connected to the Train Control Management System (TCMS).

Test bench, that involves the separation of the bogie from the car.

Inboard monitoring systems including temperature probes or accelerometers. For instance, in the 8000 -2nd rolling stock series from Metro de Madrid (MDM) there are two different temperature probes on each gearbox. One of them is under the lubricant level all the time and the other one is not. As in the previous case, this monitoring system may trigger an alarm to the TCMS, something that has proved to be satisfactory for the operator because it allowed many breakdowns to be avoided. On the other hand, it was hard to put into service, because choosing an adequate threshold for the temperature required many iterations.

Axle box bearing failures can be detected in a similar way to gearbox bearing failures.

Failure of suspension components can be monitored according to the following methods: 
Visual inspection, possibly involving the disassembly of the component.

For pneumatic secondary suspension, pressure in the air springs can be measured and monitored by the TCMS. The aim is to detect sudden pressure losses caused by a leakage in the suspension itself, to let the train driver stop the train without any safety risk (mainly derailment).

\begin{tabular}{|c|c|c|c|}
\hline Fault type & $\begin{array}{l}\text { Traditional } \\
\text { Monitoring } \\
\text { method(s) }\end{array}$ & $\begin{array}{l}\text { Novel Monitoring } \\
\text { methods }\end{array}$ & $\begin{array}{l}\text { Purpose of novel } \\
\text { Monitoring } \\
\text { methods }\end{array}$ \\
\hline $\begin{array}{lr}\text { Rolling } & \text { surface } \\
\text { defects } & \text { (flats, } \\
\text { rolling } & \text { contact } \\
\text { fatigue, defects) }\end{array}$ & $\begin{array}{l}\text { Visual } \\
\text { Wayside sensors }\end{array}$ & $\begin{array}{l}\text { Detecting high } \\
\text { values and periodic } \\
\text { patterns in axlebox } \\
\text { acceleration }\end{array}$ & $\begin{array}{l}\text { Reduce visual } \\
\text { inspection tasks and } \\
\text { unavailability time }\end{array}$ \\
\hline $\begin{array}{l}\text { Wear of wheel } \\
\text { profile }\end{array}$ & $\begin{array}{l}\text { Manual } \\
\text { measurement } \\
\text { Wayside sensors }\end{array}$ & $\begin{array}{l}\text { Detecting low- } \\
\text { amplitude hunting } \\
\text { motion of the } \\
\text { wheelset }\end{array}$ & $\begin{array}{l}\text { Provide early sign } \\
\text { of conicity increase, } \\
\text { may complement } \\
\text { data from wayside } \\
\text { stations }\end{array}$ \\
\hline Axle surface defects & Visual & $\begin{array}{ll}\text { Wayside } & \text { camera } \\
\text { system [7] } & \end{array}$ & $\begin{array}{l}\text { Reduce visual } \\
\text { inspection tasks and } \\
\text { unavailability time }\end{array}$ \\
\hline Axle crack & $\begin{array}{l}\text { Visual } \\
\text { Ultra-sonic } \\
\text { inspection }\end{array}$ & $\begin{array}{l}\text { Monitoring NxRev } \\
\text { components in } \\
\text { bending vibration of } \\
\text { the axle }\end{array}$ & $\begin{array}{l}\text { Provide continuous } \\
\text { monitoring of axle } \\
\text { structural integrity } \\
\text { and can be used to } \\
\text { complement ultra- } \\
\text { sonic inspection }\end{array}$ \\
\hline $\begin{array}{l}\text { Out of tolerance } \\
\text { critical dimensions }\end{array}$ & Manual & $\begin{array}{l}\text { Wayside optical } \\
\text { systems }\end{array}$ & $\begin{array}{l}\text { Reduce visual } \\
\text { inspection tasks and } \\
\text { optimize } \\
\text { maintenance } \\
\text { operations allowing } \\
\text { longer periods and } \\
\text { better scheduling }\end{array}$ \\
\hline Gearbox failures & $\begin{array}{l}\text { Visual (disassembly } \\
\text { may be needed) } \\
\text { Laboratory oil } \\
\text { analysis [9] }\end{array}$ & $\begin{array}{l}\text { Detecting high } \\
\text { values and periodic } \\
\text { patterns in gearbox } \\
\text { case [5] [6] }\end{array}$ & $\begin{array}{l}\text { Reduce } \\
\text { unavailability time, } \\
\text { optimize scheduling }\end{array}$ \\
\hline
\end{tabular}




\section{Needs for condition monitoring of railway running gear}

Based on the presentation of existing practice and solutions in the previous section, the following needs for future applications of $\mathrm{CM}$ in railway running gear were identified:

1) Estimation of wheel-profile parameters. Advantages here are straightforward: because it could allow postponing and planning more efficiently (from the point of view of resources) the reprofiling of the wheel without keeping the profile parameters out of the bounds specified by the standard as well as avoiding thin flange issues.

2) Determination of wheel damage: an early detection system could detect defects (flat spots, shelling, out-of-roundness, flange angles, thin flanges, etc.) even earlier than the usual procedures in preventive maintenance. This is usually done using wayside equipment, which is less expensive than using on board equipment.

3) Improvement of health monitoring of railway axles, by adapting the distance between non-destructive test (NDT) inspections to the actual service loads experienced by the wheelset and/or by implementing solutions to identify fatigue cracks in the axle based on measuring the axle's bending acceleration [27].

4) Identification of defects in bearings, to reduce in-service failures. The focus here is on early detection of faults because the time interval between correct operation and catastrophic breakdown is very short.

5) Study of the vibration in gearboxes to determine the condition of the wheelset in advance of the train being stopped for the major overhaul. 
6) Condition monitoring of vehicle suspensions, as this topic seems to be seldom covered by existing applications, despite the maintenance and replacement of suspension components takes a significant share of maintenance costs, especially for some types of railway rolling stock, e.g. long-distance and high-speed trains.

\section{Concept for a system architecture}

The CMS must be highly reliable, always available, not hindering maintenance operations, easy to maintain and must also provide enough and representative data of the variables to be studied. In particular, CMS strategies exceed the usual comparison with a threshold and usually require more complicated data processing algorithms. Therefore, the architecture of the on-board CMS should have the least possible number of sensors and reduce as much as possible the amount of data to be transferred in order to avoid high data transmission costs. However, having a small number of sensors installed at key selected positions in the bogie should continuously acquire the signals for processing, so that both analysis of the present behaviour of the bogie and prediction of its immediate future condition are made possible [11].

\section{a. Description of the CMS architecture}

The overview of the on-board CMS for assessing the performance status of bogies is presented in Figure 2. The sensors are the base nodes of the system, hereinafter designated as sensor nodes (SNs), being installed in several bogie components whose condition is to be monitored. Although the picture shows the SNs distributed among five different constituting elements, for this project they will be grouped into three sets: wheelset SNs, bearing and gearbox SNs and suspension SNs. A short and non-exhaustive list of parameters of interest is given in Table 2.

\begin{tabular}{|c|c|c|c|c|c|}
\hline Parameter & Wheels & Axles & Bearings & Gearboxes & Suspensions \\
\hline Acceleration & $\mathrm{X}$ & $\mathrm{X}$ & $\mathrm{X}$ & $\mathrm{X}$ & $\mathrm{X}$ \\
\hline Strain/stress & $\mathrm{X}$ & $\mathrm{X}$ & & & \\
\hline Displacement & & & & & $\mathrm{X}$ \\
\hline $\begin{array}{c}\text { Pressure } \\
\text { Angular velocity }\end{array}$ & & & & & $\mathrm{X}$ \\
\hline Transmission error* & & & $\mathrm{X}$ & $\mathrm{X}$ & \\
\hline Temperature & & & $\mathrm{X}$ & $\mathrm{X}$ & \\
\hline & & & & \\
\hline
\end{tabular}

Table 2: Summary of parameters of interest to monitor

The second level of the CMS is based on a dedicated box, one installed for each bogie, named Bogie Acquisition Box (BAB). The measurement signals generated by the SNs applied to each bogie are acquired by the $\mathrm{BAB}$, assuming that wired connection can be established between these two components of the system. For this case, the BAB should 
have the capability of conditioning the electrical signals and to convert them from analogue to digital format. Alternatively, these two operations could be performed at the SN level and the already digitized data sent wirelessly. In addition to acting as a junction box by gathering all the data from the SNs and routing them to the CMS third level, the BAB will acquire from the SNs, synchronize the measurement signals, buffer I/O data during transmission, store pre-processed data and supply energy for SNs, interfacing with the train communication networks, and most importantly, pre-process the raw data collected from SNs in order to extract primary features, which combined and correlated with the stored time history allows for the identification of patterns and trends divergent from the normal condition of the bogie components.

From the BABs, raw and pre-processed data are sent to the Vehicle Monitoring Box (VMB), which represents the third and higher level of the CMS at the passenger car or locomotive. This component of the CMS stores all data in an on-board mass memory storage system, and a CPU holds the functionalities to perform the configuration of the $\mathrm{BABs}$ in the corresponding vehicle. One of the main features of this unit is the integration of data supplied by multiple sources to produce more consistent, accurate, and useful information than that provided by each part (including the train location information). It will also control the transfer of data, both raw and key performance indicators (KPIs), to the visualization and control node in the train and to a wayside server located at a ground station. The higher level of the on-board CMS is the Control Station (CS), which is responsible of the storage of the data and the management of the train-to-ground (T2G) communications for the (Operations Control Centre) OCC-CMS connection. Additionally, this unit will also have some processing capability of correlation of the data gathered from all vehicles, so that the source of any inadequate behaviour can be identified (external cause, bogie related, or vehicle derived). A ground station, usually at the OCC, runs databased applications for the overall data storage and to control the train fleet operation. This station is in continuous wireless contact with the mobile stations of the running trains for the collection of recent information to update its multipurpose database. On the other hand, the ground station can be accessed by client stations, from which the system can be operated and managed. 


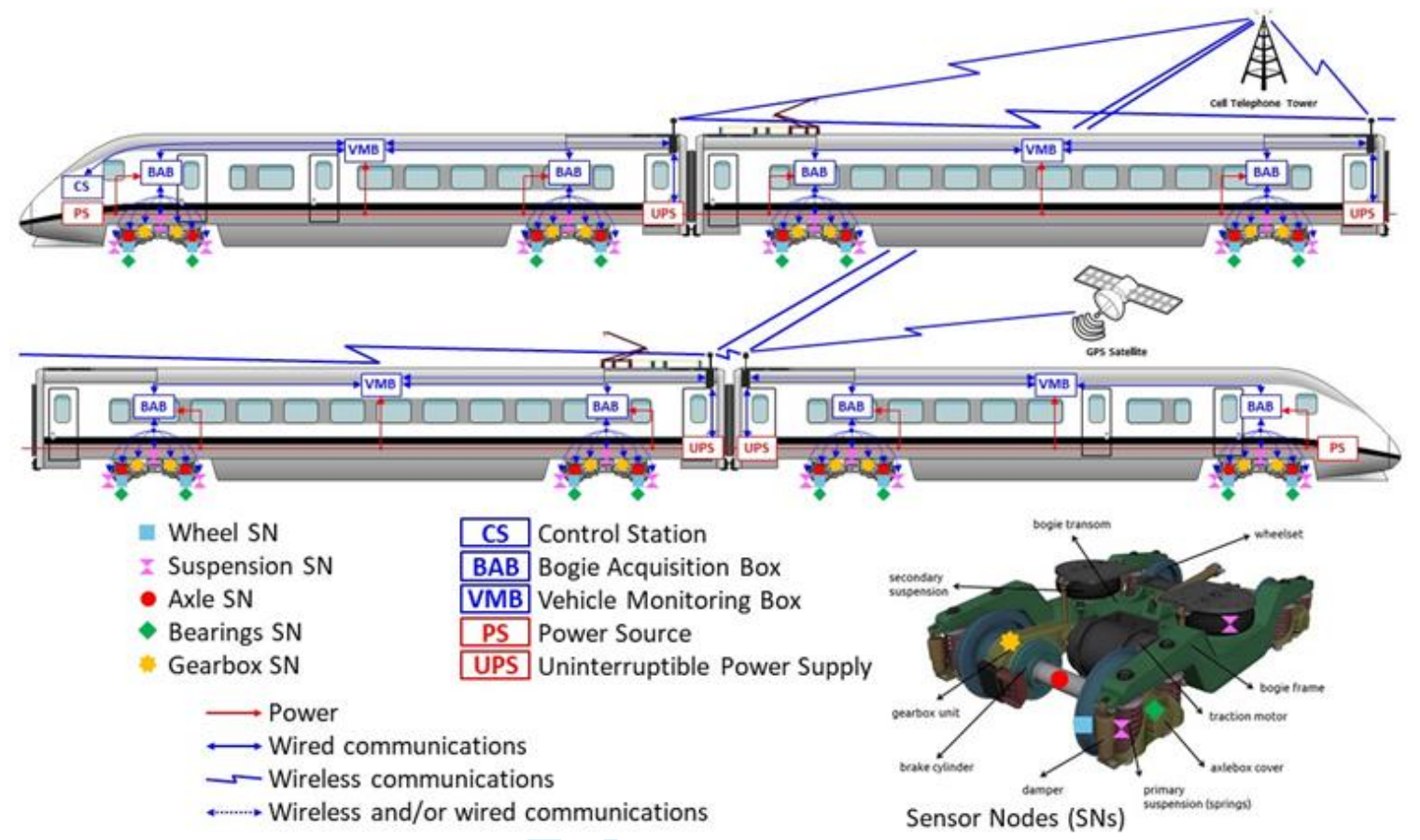

Figure 2: General overview of the on-board CM system

\section{b. Data processing, power and communications}

Regarding the processing of the data, there are two opposite architectures: the distributed and the centralized. BABs will require more computing power in the distributed architecture than in the centralized one but the volume of data that goes through the onboard network is significantly lower.

The concept behind this CM system is to develop an autonomous self-powered wireless sensor system with a significant reduction in installation costs and as easy to maintain as possible. Therefore, using wireless systems, both for communication and power, can play a decisive role. Although an usual solution, the need for regular replacement makes the use of primary batteries non-optimal. In this context of limited energy available, the on-board $\mathrm{CM}$ system requires an optimised use of energy, where power consumption should be kept as low as possible, using energy-saving techniques [12] and harvester-based powered sensors. In particular, harvesters may have the capability to obtain enough energy to power the CM system if energy harvesting units are installed at places experiencing high vibrations, typically the axle box. On the other hand, powering sensors using wires will still be useful in many cases.

Depending on their location or purpose, wireless communication systems implemented on trains can be divided into three main scenarios: train-to-ground (T2G), inter-car and intracar. For the T2G communications the most common technology choice is the public 3G$4 \mathrm{G}$ network but many operators are starting to deploy private $\mathrm{T} 2 \mathrm{G}$ networks based on IEEE 
802.11 or even $4 \mathrm{G}$ private networks [13]. The use of the railway standard GSM-R is not very common because any new interface requires an update in the safety case, which is expensive. On the other hand, GSM-R is not IP-based so flexibility is not its strength. As the amount of data to be transferred directly impacts on the power consumption, the frequency of data transmission should be considered at the design stage [12]. Regarding inter-car communications, they are essential to interconnect high-speed networks embedded in the vehicles, requiring low latencies and high data transfer rates. In each vehicle the access point (AP) acts as a client station for the AP in the previous vehicle, and as an AP for all the stations within its vehicle. With the purpose of transferring data from the vehicles to the CS at the locomotive or sending alarm messages to the train driver, a relay node is thus needed for each vehicle. Nowadays, the main technologies for inter-car communications are IEEE $802.11 \mathrm{~g} / \mathrm{n} / \mathrm{ac}$, Dedicated Short-Range Communications (DSRC), ZigBee (IEEE 802.15.4), Ultra-wideband (IEEE 802.15.4a) and IEEE 802.11p [12]. Finally, for intra-car communications the links created by the APs provide wireless access to the passengers and to the CMS nodes inside the vehicle [14]. In this scenario there is a dominant technology: the IEEE $802.11 \mathrm{~b} / \mathrm{g} / \mathrm{n} / \mathrm{ac}$ family of standards popularly known as Wi-Fi. For more information on all these wireless communications technologies see [13] [14].

\section{New technology concepts for the condition monitoring of wheelsets}

\section{a. Use of embedded sensors in wheelsets}

NDT inspection, in particular ultra-sonic inspection of railway axles, represents a fundamental part of the preventive maintenance plan for a vehicle, from the point of view of its relevance to both safety and maintenance costs. A main parameter that has to be set in the maintenance plan is the periodicity of inspection, that has to be low enough so that, if a crack was present in the component at the previous inspection but too small to be detected, it will be possible to detect it in a next inspection before a final failure takes place. Intervals are usually defined based on the previous service experience; alternatively, they could be estimated through a more scientific approach, whose aim is to predict how a prospective crack would tend to propagate under the vehicle loading conditions. Nevertheless, the reliability of such a method is limited by the fact that real distributions of loads are not available and when they are available, they are limited to a few thousand $\mathrm{km}$ of tests performed during the vehicle homologation (typically carried out for testing dynamic behavior) and so not representative of the actual service life. An innovative solution proposed in this project provides a first opportunity to rail operators to monitor in the long term bending and torsion loads in a few representative axles of a trainset. A scheme of the monitoring system for axle service loads is shown in Figure 3: it is made of a 
miniaturized intelligent sensor that is imbedded in the axle and periodically communicates through a radio connection the load data to an onboard data concentrator.

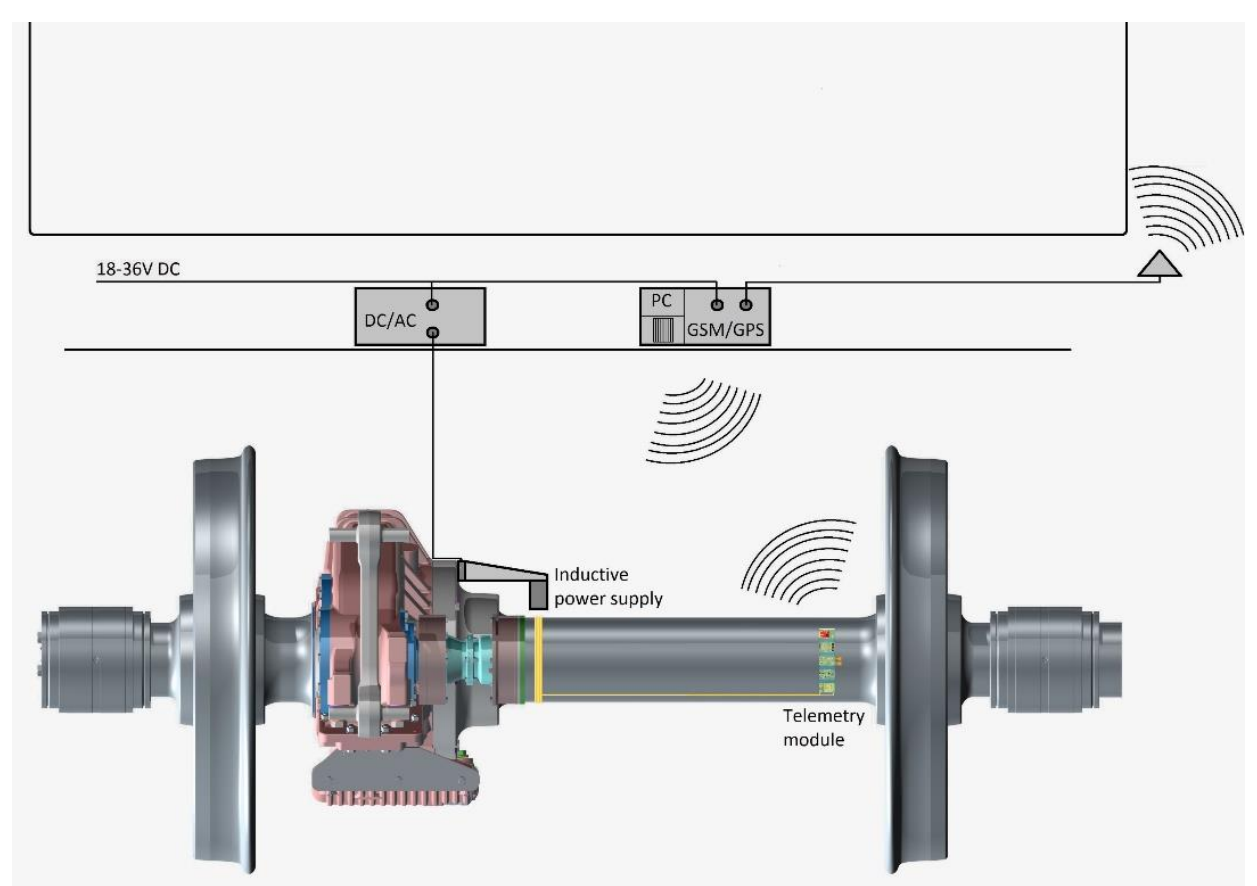

Figure 3 - Wheelset load monitoring system for optimizing the NDT inspection plan

The results that can be obtained through a load monitoring system of this type are exemplified by a pilot project performed by Lucchini RS in cooperation with Trenitalia. In this pilot project, one axle of a locomotive was instrumented with the load monitoring system and data were recorded for several months, while the locomotive was performing service on lines having different geometry. Some lines were along mountain paths and included more curves thereby producing relatively high loads in the axle, other ones were laid on relatively flat ground, resulting in less intense bending and torsional stresses in the axle. Through the use of geolocalization of the vehicle, it was possible to generate separate load spectra for the different lines and using appropriate crack propagation models, the corresponding crack propagation curves were obtained. Figure 4 shows the normalized propagation curves resulting from the stresses measured on different lines. In the abscissa, the distance run by the axle is normalized by the propagation distance estimated for the reference combined service spectrum (the continuous red line in the diagram). This representation clearly shows that the inspection interval in the case of the Adriatic line can be $20 \%$ larger than the combined service for the Apennine line 2; on the other side, according to the simulation, the exclusive service on railway lines with a severity level like Apennine line 1 would result in a shorter (about 50\%) inspection interval than the combined service. 


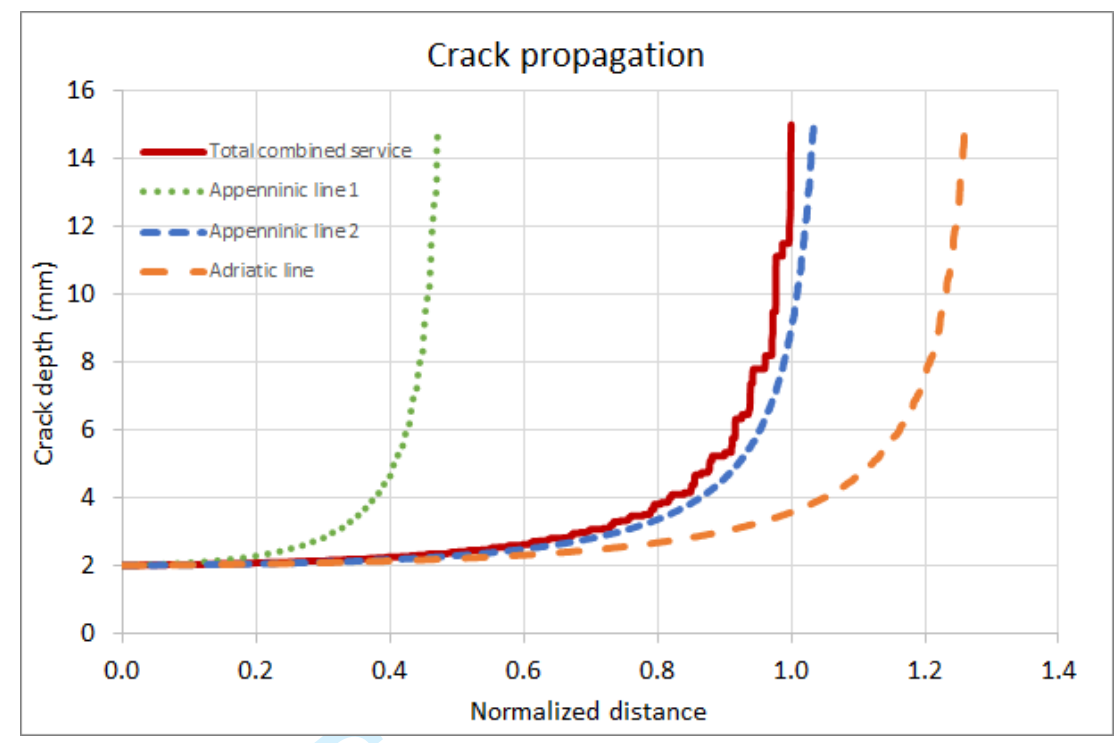

Figure 4 - Crack propagation for different in-service measured load spectra.

\section{b. Monitoring of wheel/rail contact forces}

The monitoring of axle load spectra can be expanded in a relatively straightforward way to also encompass the monitoring of wheel/rail contact forces, which is instrumental to enhancing running safety (e.g. by enabling advanced derailment detection or instability detection systems), condition-based vehicle maintenance, improvement of wheel/wheelset design. In RUN2Rail, the feasibility of simple low-cost strain-gauge-based techniques to quantify wheel/wheelset load spectra was assessed.

Wheel-rail contact forces (components $\mathrm{Y}$ and Q) are routinely measured when placing a vehicle type on the market. In Europe, the purpose of the measurements is the assessment of running safety and track loading (TSI Loc\&Pas Section 4.2.3.4 [16], EN 14363, [17]). The measurements are usually performed by means of strain gauges applied to the wheel and/or the axle (for a description of the existing methodologies see [18]). A telemetry is required to transmit the signals from the rotating wheel/wheelset to the on-board part of the measurement chain since the signals cannot be logged but must be available in realtime. The setups for this kind of measurement are quite complex and costly, the required accuracy is quite high, and their life-time is not required to be long. On the other hand, Wheel/wheelset In-Service Force Monitoring (WISE-FM) has seen few applications (e.g. in Japan [19], [20]). The uses of in-service monitoring are in principle several - related e.g. to safety, condition-based vehicle maintenance, improvement of wheel/wheelset design through a better knowledge of load spectra. 
In this work, a system previously developed for high-accuracy applications (Alessandria et al. [21]) was simplified by searching for configurations based on only 1 or 2 channels per wheel were considered. Six types of strain-gauge (SG) configurations (with some variants) and 4 characteristic points of the "gauge-side" inner wheel surface, known from previous research, were screened through Finite Element Analysis using a previously validated model of a Lucchini - Alstom wheel designed for the class ETR 450 "Pendolino" trainset, as reported more in detail in Velletrani et al. [22]. Figure 5 shows the 2-channel configuration that proved to be most suitable. It is based on full SG bridges connecting SGs positioned in points of opposite radii on adjacent sides of the bridge, all on the inner side of the wheel. Measuring the vertical force $\mathrm{Q}$ and lateral force $\mathrm{Y}$ is possible when the instrumented diameter is vertical ("Distance-Based Sampling" technique, with two samples per wheel-revolution). The accuracy estimated for the vertical force is approximately $8 \%$ of the measuring range $(100 \mathrm{kN})$, whilst for the lateral force it is $4 \%$ of the measuring range $(50 \mathrm{kN})$. It was also found that the longitudinal force component $\mathrm{X}$ should be measurable with reasonable accuracy when the diameter is horizontal. Importantly, if the system is used for the construction of wheel load-spectra, numerical experiments showed that the system would allow the detection of impact loads caused e.g. by joints or crossings, but with 2 "blind spots" (in the vicinity of the $90^{\circ}$ angular positions) of about $2 \times 15^{\circ}=30^{\circ} / \mathrm{rev}$, i.e. $1 / 12$ of a revolution. This means that on average 1 out of 12 impacts could go undetected, but also that more than $90 \%$ of impacts could be detected.

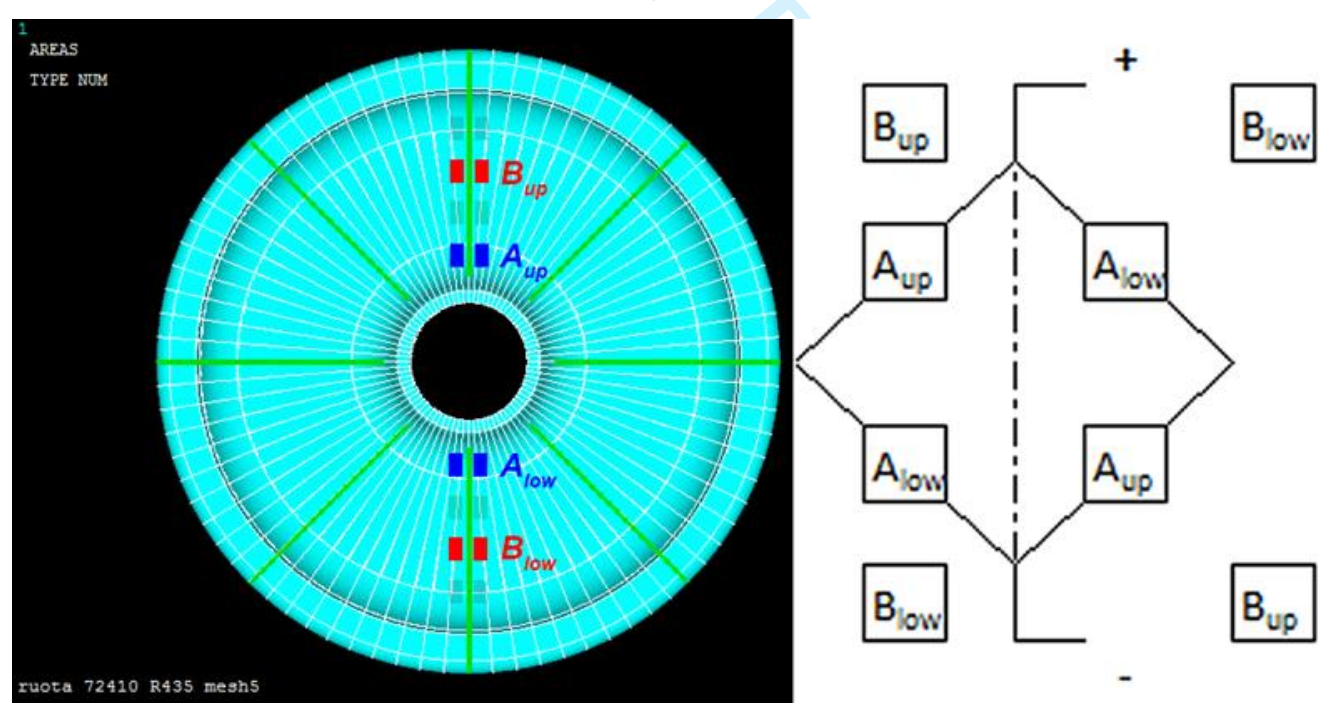

Figure 5 - Adopted configuration: Full Bridges respectively in $A(Y)$ and $B(Q, X)$.

c. Monitoring of wheel defects through embedded sensors

Having embedded sensors installed in the wheelset also provides an efficient opportunity to monitor axle vibration, enabling the early detection of defects in the rolling surface such as wheel flats or localized RCF damage. In RUN2Rail, a new concept was derived, 
considering the installation of MEMS accelerometers inside the bore of a hollow wheelset axle, as shown in Figure 6. The advantage of this solution is that the CM system is embedded in the wheelset, resulting in easier installation and excellent protection from shocks, flying ballast stones, vandalism etc. MEMS acceleration sensors are installed on a board which also provides powering through batteries (a solution for wireless power supply is under development) and low-consumption Wi-Fi transmission of the measured signals to the BAB. Testing of the system is ongoing on a full-scale roller rig "BU300" at Lucchini RS premises, see Figure 6.

On this test rig a full-scale wheelset is being tested in different running conditions first in new condition without defects and then with a wheel flat generated artificially. The wheel flat at the beginning had a limited length of $10 \mathrm{~mm}$ and was gradually enlarged to $50 \mathrm{~mm}$. By analyzing the RMS and the Crest Factor of the vibration measured at different running speeds as shown in Figure 8, it is possible to identify the presence of the wheel flat starting from a size of $30 \mathrm{~mm}$ (WF4) and then $40 \mathrm{~mm}$ (WF5); smaller flats are instead covered by the normal vibration generated during the wheelset rotation.

The possibility to obtain this indication automatically during real service, enables the maintenance manager to effectively schedule in advanced the wheel reprofiling limiting the unavailability of the vehicle; moreover, this kind of continuous monitoring will eliminate the need for periodic visual inspections of the wheels considered to be time consuming and not always sufficiently accurate.
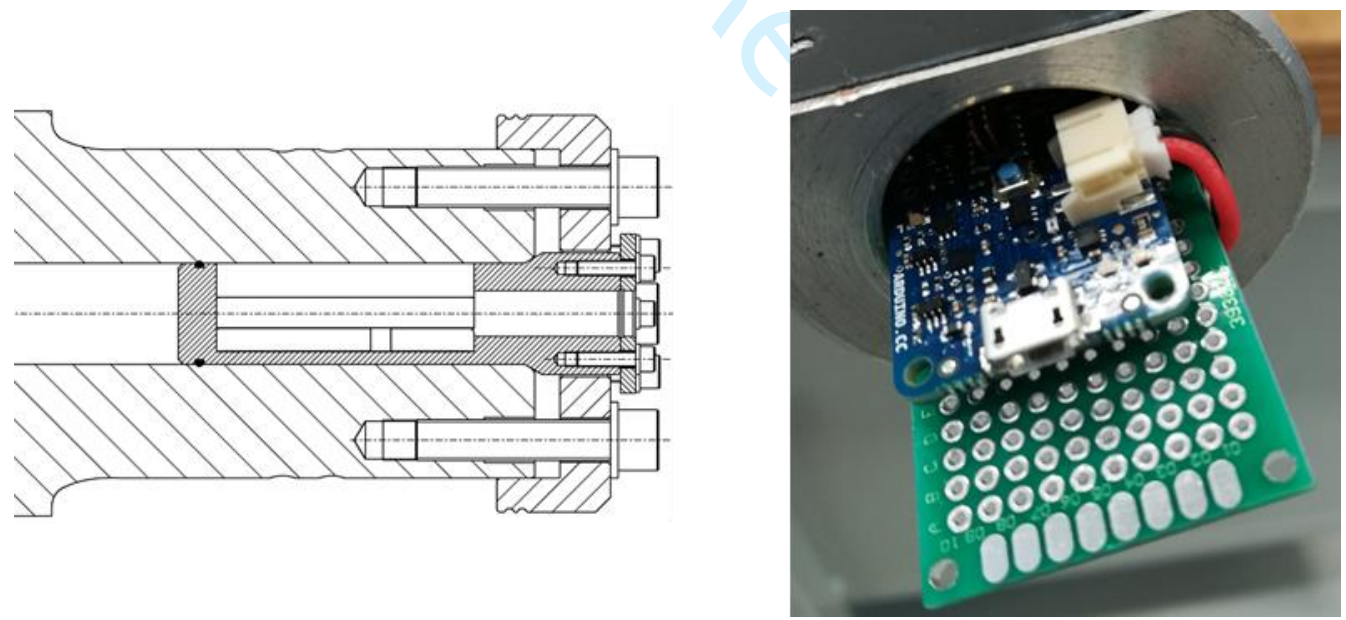

Figure 6 - Embedded MEMS sensors for monitoring wheel surface condition 


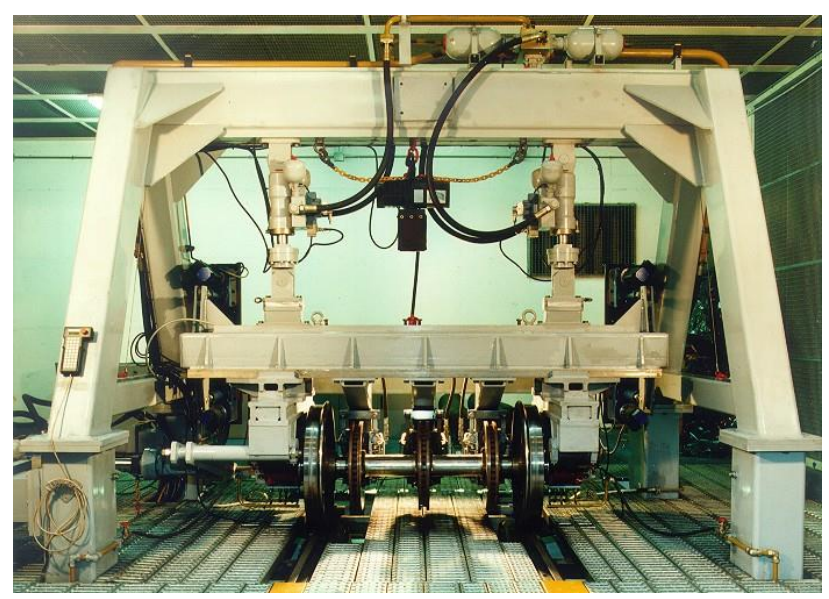

Figure 7 - BU300 roller rig

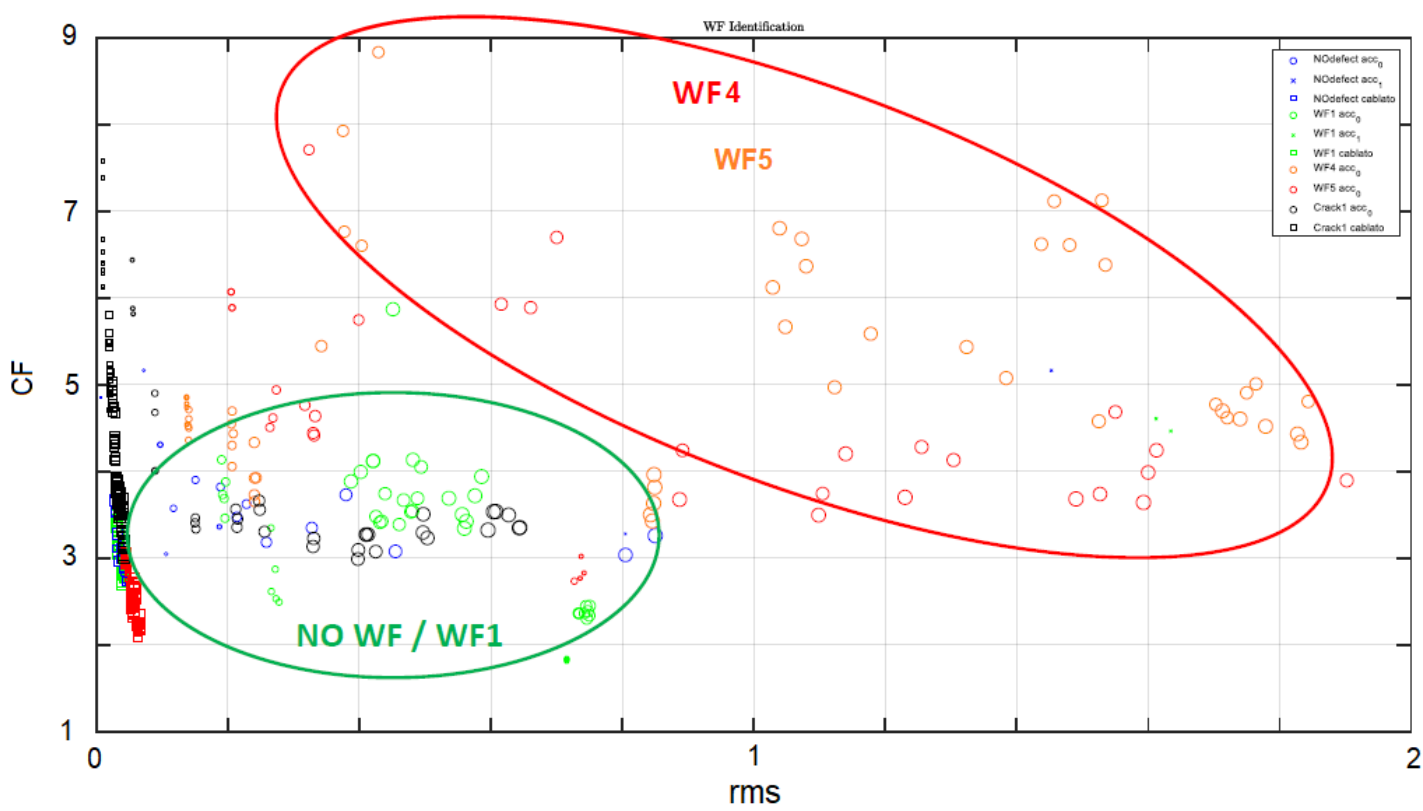

Figure 8 - Results of roller rig tests with different size of wheel flat defects. Crest factor (CF) vs. rms of the axle-box acceleration signal. The green and red ellipses enclose results for small/no wheel flat and for large wheel flats respectively

\section{New technology concepts for the condition monitoring of bearings and gearboxes}

For the condition monitoring of bearings and gearboxes, two possible measuring set-ups were considered:

Accelerometers on gearbox housing, close to bearings: this is a rather classical strategy for gearbox monitoring, with the main advantage of an easy implementation. 
Several Condition Indicators (CI) relevant to monitor gears and bearings can be extracted from the measured signals and used to detect faults. Moreover, in recent years Machine Learning (ML) algorithms have been proposed for monitoring applications because of their ability to detect new events or faults. The combination of Condition Indicator computations with ML algorithms proved in this project to provide a satisfactory solution to the detection of early-stage faults in the powertrain.

VIBRATEC has set-up a test bench in order to carry out fatigue tests on gears (see Figure 9). This test bench is composed of 2 electrical motors. One is used as a motor, the second one as a brake to apply a given torque. The studied system is composed of 2 shafts on which spur gears are mounted. A relatively bad class of gear is voluntarily chosen to improve the ability to damage the gear contact area, and to lead to a crack on the tooth base. The test bench instrumentation is mainly composed of vibration sensors (accelerometers) and rotational speed sensors. Accelerometers and some rotational speed sensors are used for the vibration analysis, and only rotational speed sensors are used for the instantaneous angular speed (IAS) analysis.

The fatigue test consists of a continuous run with a start at healthy condition. Measurements are done periodically until a failure appears. After applying the post-processing (using the toolbox developed), an observation is realized on all CI computed. To remember, at the beginning, the system is in healthy condition and at the end 2 teeth are broken.

Looking to the CIs ER (energy ratio) and MA6* (surface damage indicator, see Table 4 1) on differential TSA signals, the fault may be clearly established before the failure (the complete crack of the tooth). Figure 10 illustrates the evolution of these $2 \mathrm{CI}$ during this fatigue test. Looking to these specific indicators, the fault detection is possible since measurement 5 for a failure which appears just after measurement 13 . This represents a detection more than 5 hours before the crack, which is equivalent to around $25 \%$ of the lifetime. This result is really encouraging, but it remains coming from laboratory measurements, a real validation with measurement on-board would be the best validation of this toolbox. 


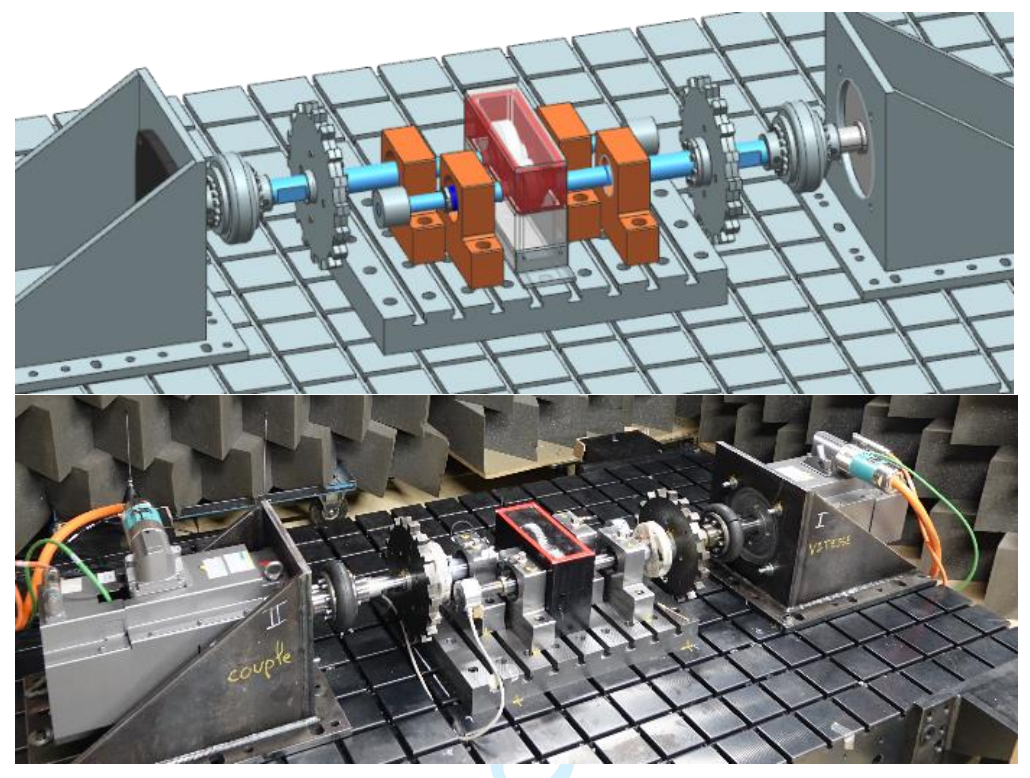

- 2 electrical motors: $15 \mathrm{~kW}$

- max torque: 150 N.m

- max speed: 6000rpm

- 4 ball spin bearings

- 1 spur gear stage

- Number of teeth: $42 / 55$ teeth

- Gear quality class: 9

Figure 9 - Test bench for experiments on gearbox monitoring at VIBRATEC

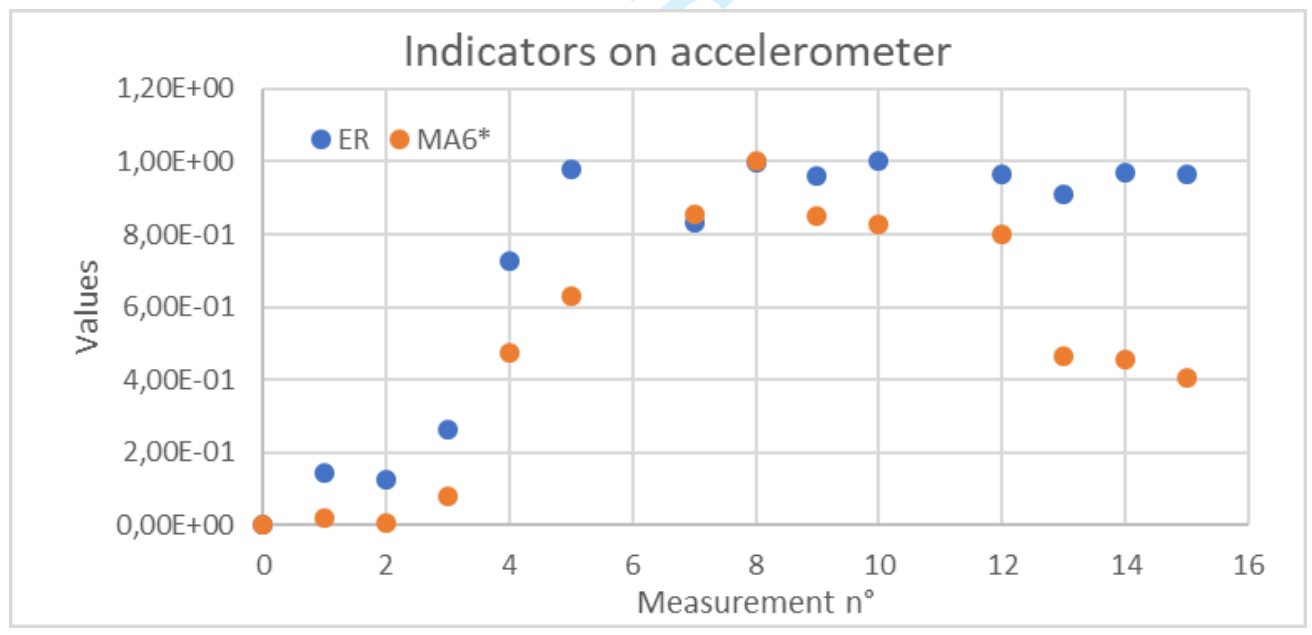

Figure 10 - Trend of condition indicators ER and MA6 obtained from the measured acceleration signals

\section{New technology concepts for the condition monitoring of suspension components}

This case study envisages the use of sensors and of a condition monitoring system (CMS) to monitor the health state of various suspension components including dampers, coil springs, pneumatic springs and other. The approach investigated is to use signals from 
Figure 11 - Configuration of accelerometer sensors for fault detection in primary suspension components.

Different fault detection schemes were devised and assessed through numerical simulations performed using a multi-body model of a passenger vehicle. The multi-body model was used to produce 'virtual measurements' for the sensors shown in Figure 11 corresponding to different running conditions and to a different health state of the suspensions, i.e. for a healthy suspension, represented by the nominal value of suspension parameters, and for different fault types which were modelled as a change in the stiffness and/or damping parameters of the suspension. It is worth mentioning that the multi-body model of the vehicle reproduces at a quite good level of detail the actual primary suspension arrangement including, in particular, the kinematics of the swing arm and the internal flexibility of primary dampers resulting from oil compressibility and from the flexibility of the end mountings.

For the sake of brevity, here only one method is considered which consists of the combination of Recursive Least Squares (RLS) estimation of suspension parameters, combined with the use of an outlier detection technique known as Mahalanobis Squared Distance (MSD). The equation used for suspension parameter estimation is the one describing the vertical motion of the bogie under the action of forces coming from primary and secondary suspensions and is as follows:

$$
M_{f} \ddot{Z}_{f}(t)=\sum_{i=1}^{4} C_{p i} V_{p i}(t)+\sum_{i=1}^{4} K_{p i} D_{p i}(t)+v_{z}
$$


where:

- $\quad M_{f}$ is the known mass of the bogie frame;

- $\quad \ddot{Z}_{f}$ is the vertical acceleration of the bogie frame which is obtained as a linear combination of the signals from the bogie-mounted sensors;

- $\quad \mathrm{C}_{\mathrm{pi}}$ and $\mathrm{K}_{\mathrm{pi}}$ are the unknown damping and stiffness parameters of the primary suspension with subscript $i=1 \ldots 4$ denoting the front right, front left, back right and back left corner of the bogie frame;

- $\quad$ Vpi is the speed of elongation the primary suspension at the i-th corner, obtained from the integration of the measured acceleration signals;

- Dpi is the elongation the primary suspension at the i-th corner, obtained from the double integration of the measured acceleration signals;

- $\quad v_{z}$ is a random disturbance representing the effect of modelling errors.

The direct use of equation (1) requires the double integration of acceleration signals to derive the relative displacements of across the primary suspension end mountings. Therefore, parameter estimation is performed using the time derivative of equation (1):

$$
M_{f} \dddot{Z}_{f}(t)=\sum_{i=1}^{4} C_{p i} A_{p i}+\sum_{i=1}^{4} K_{p i} V_{p i}+v_{\dot{z}}
$$

with $A_{p i}$ the relative vertical acceleration of the points at which primary suspension are attached and $v_{\dot{z}}$ a random noise term to consider modelling errors.

The 8 unknown damping and stiffness parameters of the primary suspension $\mathrm{C}_{\mathrm{pi}}$ and $\mathrm{K}_{\mathrm{pi}}$ are determined as the ones providing the best fit of Eq. (2) for the measured acceleration signals. To this aim, the Recursive Least Square (RLS) [24] or the Damped Least Square (DLS) [25] methods are used. In both cases, a bias is observed in the estimation, which is due to the following effects:

i) A reduced set of sensors is used, see Figure 11, whilst a more precise estimation of suspension parameters could be obtained measuring the vertical acceleration at all axle-boxes;

ii) In Equations (1) and (2) the effect of the forces transmitted by the secondary suspension to the bogie frame is neglected. This effect could actually be considered, but would require that also the acceleration over the car body is measured;

iii) Equations (1) and (2) imply a simplified model of the primary suspension, seen as a spring and damper in parallel. In particular, this model neglects the effect of internal flexibility of primary dampers.

To reduce the effect of estimation bias on fault detection, the values of the stiffness and damping parameters obtained from the RLS/DLS estimation are processed according to the outlier detection technique known as Mahalanobis Squared Distance (MSD) [26, 27] so 
that the fault can be detected based on the deviation of the set of estimated parameters from the values corresponding to the 'nominal' behaviour of the suspensions. A population of 'healthy suspension' cases was created considering different running conditions (e.g. different vehicle speeds and track irregularities) for the vehicle with primary suspensions in nominal condition. This population was used to form a base set towards which any next estimation of suspension parameters is tested by the outlier detector to find a deviation from the trend of healthy parameters, eventually enabling to point out a deviation from the healthy condition. This scheme can be applied using different sub-sets of estimated parameters, i.e. besides an 8D space considering all estimated parameters, two 4D spaces considering only stiffness parameters and only damping parameters, or sub-sets representing the values estimated for the left/right side or front/rear side of the bogie. This enables the isolation of faults, i.e. besides pointing the occurrence of a fault (so-called "fault detection") the classification of the fault as one happening in a spring or damper and possibly also the corner in the bogie where the fault is happening. Due to space limitations, here only two exemplary result are shown.

Figure 12 shows the values of the MSD condition indicators built using the estimated primary vertical stiffness parameters (in red) and primary damping parameters (in blue) for faults in primary springs having different degrees of severity which were simulated in the multi-body model through a reduction of the primary stiffness in just one corner of the bogie by an amount ranging from 20\% (low severity) to $100 \%$ (high severity). To improve the readability of the diagrams, the range of the vertical axis is limited to a maximum value MSD $=5000$ and values of MSD greater than this limit are plotted on the upper border of the plot. In the headings, FR, FL, BR and BL stand respectively for front right, front left, rear right and rear left and denote the specific corner where the fault was applied. 

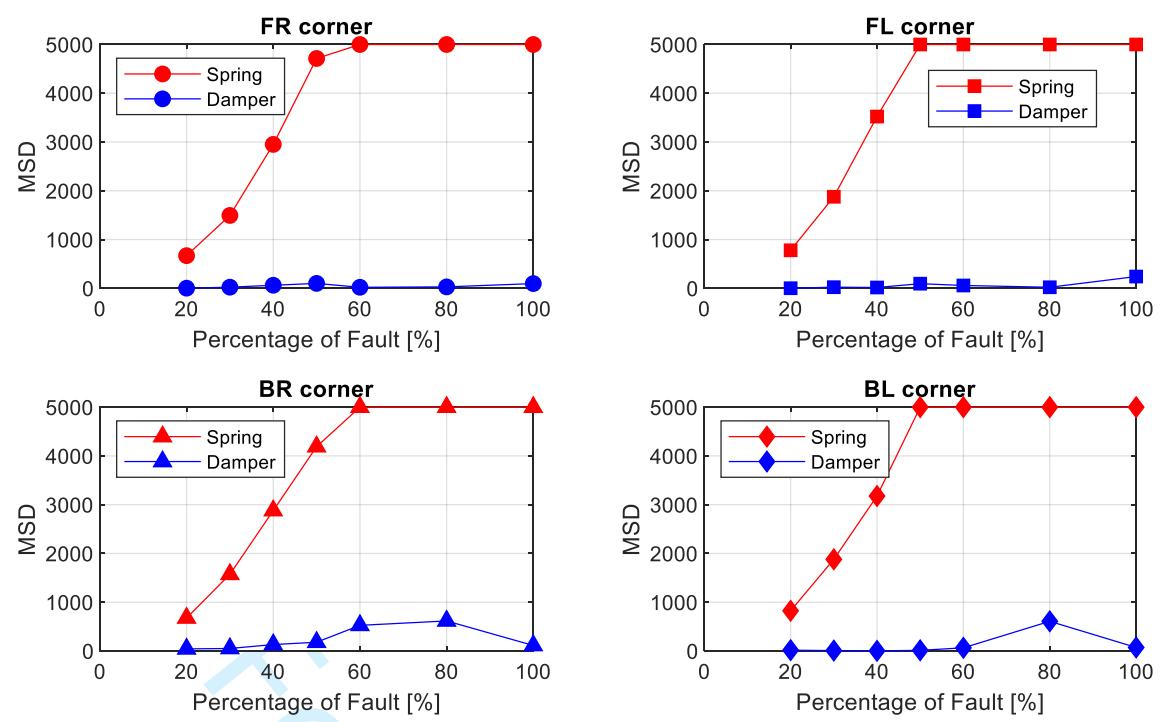

Figure 12 - MSD condition indicator for faults of different severity in primary vertical springs (stiffness reduction $20-100 \%$ )

These results show that the MSD built using the estimated primary vertical stiffness parameters (red line) is rapidly increasing with the severity of the fault in a spring, so that taking a proper threshold value (e.g. MSDThreshold=1000) allows the recognition of the presence of a fault occurring in a primary spring located at any corner of the bogie, even in case the severity of the fault is low (e.g. decrease of stiffness in the range of $30 \%$ ). Furthermore, the MSD built using the estimated values of the primary dampers (blue lines) remains very low for all the conditions considered, enabling a clear and reliable isolation of the fault, i.e. enabling to discern a fault happening in a primary spring from one happening in a primary damper. The monotonically increasing trend of the MSD built using the estimated primary vertical stiffness parameters also shows the possibility to obtain an indication concerning the severity of the fault.

In Figure 13, the dual case of Figure 12 is considered: in this case, faults with different severity corresponding to the reduction of the damping coefficient in just one corner by an amount from 20\% to 100\% are considered. The same MSD indicators shown in Figure 12 are plotted vs. fault severity, showing in this case that MSD indicator built using the estimated stiffness coefficients are insensitive to a fault occurring in one damper, whilst the MSD indicator built using the 4 estimated damping values is highly sensitive to the fault and shows a monotonically increasing trend with the severity of the fault. 

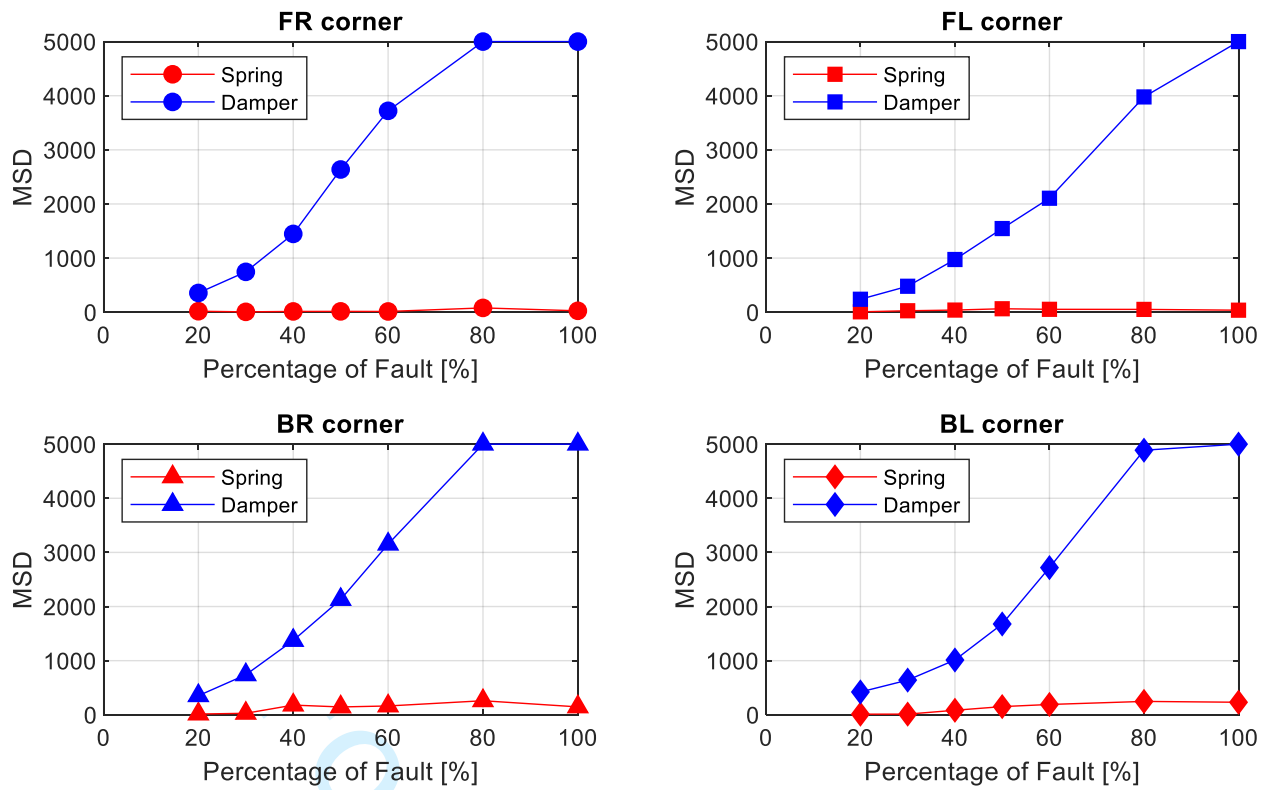

Figure 13 - MSD condition indicator for faults of different severity in primary vertical dampers (damping reduction $20-100 \%)$

\section{Impact analysis}

In the RUN2Rail project, an impact analysis was performed considering a benchmark scenario built upon a Metro de Madrid trainset running on a line in Madrid, and an innovation scenario in which the current trainset is replaced with a similar mechanical configuration but with a CMS based on the technology concepts described above.

The quantitative economic analysis is reported separately. The results summarised qualitatively in Table 3 strictly refer to the case study. However, with caution, they may be used as indications for other cases. The convenience of adopting a CMS for a given running-gear sub-assembly was in fact shown to depend most of all on the failure rate of the sub-assembly and the assumptions on the occurrence of future unavailability events and their penalty costs, both factors that can change significantly from operator to operator.

As to the potential impacts, the CMS can broadly be divided into two parts regarding the potential impacts: the part dedicated to in-service load monitoring (instrumented wheelset), that needs to be installed on only a few trainsets of a fleet, and a running-gear defect CMS (wheelset, gearbox and suspension CMS) to be installed on all trainsets. The types of benefits are distinct, as may be seen in Table 3. Of the categories considered, inspired to those of the Universal Cost Model initiated in the ROLL2RAIL EU project, those most impacted by the in-service load monitoring CMS are passenger revenue, energy consumption, track maintenance (all light-weighting related) and wheel maintenance. Those most impacted by the defect detection CMS are track maintenance and, above all, service and trainset unavailability. 
Hazard impacts were considered to be nil since the analysis considered the defect detection systems only for their maintenance-related effects, and in any case the introduction of the CMS must not affect existing safety levels negatively. Desirable positive safety impacts could be associated with the defect detection systems, which may be used to prevent catastrophic failures also. This type of application requires however a high level of redundancy (and much higher cost) in order to avoid negative implications on availability (e.g. "false alarms" affecting service) and was not explored in detail.

All in all, for the case study considered in which the track maintenance benefits are reaped by the same company that operates the trains, the overall benefits were shown to justify an investment in the order of $5 \%$ of the current trainset acquisition cost.

\begin{tabular}{|c|c|}
\hline \multicolumn{2}{|r|}{ (a) Wheelset CMS for in-service loads } \\
\hline Impact category & Description \\
\hline Passenger revenue & \multirow{3}{*}{$\begin{array}{l}\text { Benefit due to the possibility of reducing unsuspended mass } \\
\text { in the second part of the trainset's lifetime due to the } \\
\text { knowledge of actual loads in the first part }\end{array}$} \\
\hline Energy & \\
\hline Track maintenance & \\
\hline Wheel maintenance & $\begin{array}{l}\text { Almost immediate benefit due to the possibility of adapting } \\
\text { maintenance intervals to actual loads }\end{array}$ \\
\hline \multicolumn{2}{|c|}{ (b) CMS for defects (wheelset, gearbox, suspension) } \\
\hline Impact category & Description \\
\hline Track maintenance & $\begin{array}{l}\text { Immediate benefit due to fewer defective components in } \\
\text { operation }\end{array}$ \\
\hline Unavailability & $\begin{array}{l}\text { Immediate benefit due to the possibility of: } \\
\text { - early identification of defects before they create problems } \\
\text { service unavailability (delays, unexpected withdrawal from } \\
\text { service) } \\
\text { - better scheduling of workshop occupancy based on the } \\
\text { information on impending defects, with reduction of trainset } \\
\text { unavailability }\end{array}$ \\
\hline
\end{tabular}

Table 3: Summary of impacts, (a) CMS for in-service wheelset loads, (b) CMS for component defect detection in support of maintenance activities 

passenger railway vehicles which were elaborated in the project RUN2Rail. After an examination of existing solutions and needs for further research work, a general architecture for several running-gear CMS-related use-cases was defined. Finally, new ideas and concepts for health monitoring and detection of faults were presented, considering three case studies:

1. monitoring of wheelsets;

2. monitoring of railway gearboxes, including bearings and gear teeth faults;

3. monitoring of suspension components.

As far as case 1 is considered, the work done resulted in the definition of algorithms for processing stress and acceleration signals measured on-board a railway wheelset to support the NDT inspection of axles and to detect defects on the rolling surface of the wheels. It also resulted in a feasibility analysis for a strain-gauge-based system for monitoring wheelrail contact forces.

As far as the monitoring of gearboxes and bearings is concerned, a suite of signal analysis methods was developed, which enables the automatic processing of the measured signals to elaborate several different condition indicators and implements Machine Learning algorithms for fault detection and classification. The suitability of this approach was assessed using measurements taken in a run-to-fail test performed on a gearbox in a test bench. The results obtained in this test show that the tools developed in this work can detect an incipient failure of the gearbox several hours in advance before the failure leads to serious damage causing loss of gearbox functionality.

Finally, regarding case study 3, the work performed was aimed at assessing different methods for condition monitoring and fault detection of faults in the primary suspension of the bogie. The results obtained show the potential to detect and isolate faults in primary springs and primary dampers even in case of low severity of the fault.

It is important to underline that all the methods described in this paper can be applied using relatively simple sensors and data acquisition / data processing systems so that the additional cost implied by the condition monitoring system can be kept to a minimum and the use of Commercial-Off-The-Shelf products is possible.

The potential impacts of the adoption of the systems strongly depend on conditions such as the current failure rates of the sub-assembly to be monitored and the costs of unavailability due to running gear faults. These are highly case-dependent. The case study developed shows that significant benefits could be obtained due to light-weighting, thanks to the knowledge of actual in-service loads, and to avoidance of trainset and service unavailability, thanks to the early detection of faults. 


\section{REFERENCES}

[1] "RUN2Rail Project (RUN2RAIL (Innovative RUNning gear soluTiOnsfor new dependable, sustainable, intelligent and comfortable RAIL vehicles)," [Online]. Available: http://www.run2rail.eu.

[2] "Shift2Rail” [Online]. Available: https://shift2rail.org/.

[3] H. Mihaly, "From NASA to EU: the evolution of the TRL scale in Public Sector Innovation," The Innovation Journal: The Public Sector Innovation Journal, vol. 22(2), pp. 1-23, 2017.

[4] J. Zhu, T. Nostrand, C. Spiegel and B. Morton, "Survey of condition indicators for condition monitoring systems," in Annual Conference of the Prognostics and Health Management Society, Fort Worth, Texas, 2014.

[5] V. Sharma and A. Parey, "A review of gear fault diagnosis using various condition indicators," Procedia Engineering (12th International Conference on Vibration Problems, ICOVP 2015), vol. 144, pp. 253-263, 2016.

[6] A. Aherwar and S. Khalid, "Vibration analysis techniques for gearbox diagnostic: A review," International Journal of Advanced Engineering Technology, vol. 3, no. 2, pp. 04-12, 2012.

[7] Perpetuum, "Rail Applications," Perpetuum, [Online]. Available: https://perpetuum.com/rail-applications/.

[8] SKF, "SKF Insight Rail," 2017. [Online]. Available: http://www.skf.com/us/industry-solutions/railways/condition-monitoring/skf-insightrail.html.

[9] A. Almasi, "Oil analysis methods and lubrification monitoring," Plant Services, 2014.

[10] "Detector for the predictive diagnosis of faults in medium- and high-power gear boxes". Patent EP 1795892 A1.

[11] MAXBE, "Deliverable 6.2: Onboard systems installation," MAXBE Interoperable monitoring, diagnosis and maintenance strategies for axle bearings (wwwm.maxbeproject.eu), 2014.

[12] P. Fraga-Lamas, T. Fernández-Caramés and L. Castedo, "Towards the Internet of Smart Trains: A Review on Industrial IoT-Connected Railways," Sensors, vol. 17, no. 6, p. 44, 2017.

[13] J. Moreno García-Loygorri, J. Riera and C. Rodríguez, Wireless Communication Systems for Urban Transport, InTech, 2017.

[14] HUT - Communications Laboratory, "S-72.3240 Wireless Personal, Local, Metropolitan and Wide Area Networks," Course of the Department of Communications and Networking, 2006. [Online]. Available: http://www.comlab.hut.fi/studies/3240/luentokalvot/1_introduction.ppt.

[15] Bombardier Transport, "FLEXX Bogies at the Forefront of High Speed Expertise," $2008 . \quad$ [Online]. Available: https://www.bombardier.com/content/dam/Websites/bombardiercom/supportingdocuments/BT/Bombardier-Transportation-Bogies-FLEXX-High-Speed.pdf. 
[16] Commission Regulation (EU) No1302/2014, "Concerning a technical specification for interoperability relating to the 'rolling stock - locomotives and passenger rolling stock' subsystem of the rail system in the European Union," 2014.

[17] EN14363:2016+A1:2018, "Railway applications - Testing and Simulation for the acceptance of running characteristics of railway vehicles - Running Behaviour and stationary tests".

[18] A. Bracciali, C. F. and M. Macherelli, "Review of instrumented wheelset technology and applications," In Proc. 2nd Int. Conf. Railway Technol., Res., Develop., Maintenance, pp. 1-16, 2014.

[19] A. Matsumoto, Y. Sato, H. Ohno, M. Shimizu, J. Kurihara, M. Tomeoka and M. Mizuno, "Continuous observation of wheel/rail contact forces in curved track and theoretical considerations," Vehicle system dynamics, vol. 50(sup1), pp. 349-364, 2012. [20] A. Matsumoto, Y. Sato, H. Ohno, M. Tomeoka, K. Matsumoto, J. Kurihara and T. Nakai, "A new measuring method of wheel-rail contact forces and related considerations," Wear, vol. 265, no. 9-10, pp. 1518-1525, 2008.

[21] M. Alessandria, B. Dotta and R. Licciardello, "Long-term contact force measurements with the CML method", Ingegneria Ferroviaria, Vol. 66, No. 11, p. 929-948, 2011.

[22] F. Velletrani, R. Licciardello and M. Bruni, "Intelligent Wheelsets for the trains of the future: the role of in-service wheel-rail force measurement", Ingegneria Ferroviaria (in press).

[23] J.L. Gomez et al., "Angular modeling of a rotating machine in non-stationary conditions: Application to monitoring bearing defects of wind turbines with instantaneous angular speed," Mechanism and Machine Theory, vol. 136, pp. 27-51, 2019.

[24] Liu, X. - Alfi, S. - Bruni, S.: An efficient recursive least square-based condition monitoring approach for a rail vehicle suspension system, Vehicle System Dynamics, vol. 54, no. 6, p. 814-830, 2016.

[25] Levenberg, K.: A Method for the Solution of Certain Non-Linear Problems in Least Squares, Quarterly of Applied Mathematics, vol. 2, no. 2, p. 164-168, 1944.

[26] Mahalanobis PC. On the generalized distance in statistics. National Institute of Science of India, 1936, http://bayes.acs.unt.edu:8083/BayesContent/class/Jon/MiscDocs/1936_Mahalanobis.pdf. [27] M. Hassan and S. Bruni, "Experimental and numerical investigation of the possibilities for the structural health monitoring of railway axles based on acceleration measurements," Structural Health Monitoring, vol. 18, no. 3, pp. 902-919, 2019.

[28] Continental, "Sensor Technology Makes ContiTech Air Springs Intelligent," 24 April 2017. [Online]. Available: https://www.continental-corporation.com/en/press/pressreleases/sensor-technology-makes-contitech-air-springs-intelligent--70630. 